\title{
Patient adherence with COPD therapy
}

\author{
C.S. Rand
}

\begin{abstract}
Although there are very few published studies on adherence to treatment regimens in chronic obstructive pulmonary disease (COPD), the evidence that exists suggests that, as with asthma therapy, adherence is poor.

Patient beliefs about COPD, as well as their motivation and expectations about the likelihood of success of medical interventions, can influence adherence rates. Other critical factors include the patient's understanding of their illness and therapy, and the complexity of the prescribed treatment regimen. Incorrect inhaler technique is also a common failing.

When prescribing in primary or specialist care, healthcare professionals should address adherence as a vital part of the patient consultation. Improved patient education may also increase adherence rates.
\end{abstract}

KEYWORDS: Adherence, chronic obstructive pulmonary disease, compliance, health behaviour ver the past 30 years, the scientific literature describing the medicationtaking behaviour of patients has been both extensive and remarkably predictable in its documentation of the ubiquity of patients' underuse of chronic therapies [1]. While the consistency of these observations has remained unchanged, the literature on patient adherence has recently shown a shift in the terminology used to describe both patient therapeutic behaviour and the associated philosophy of the clinician-patient relationship [2].

The earliest studies of medication-taking behaviour refer to patient "compliance", which is generally described as the degree to which patient behaviour coincides with the clinical prescription [1]. Yet even 30 years ago, SACKETT and HAYNES [1] described the word "compliance" as potentially troublesome, since by definition it implies a one-sided paternal relationship, with the patient as the passive recipient of a clinical edict. Within this framework, patients can either yield to the wisdom of the doctor ("good patient") or defy doctor's orders ("bad patient"). The term "adherence", on the other hand, suggests a more willing partnership between clinician and patient and, as a result, has largely replaced the term compliance in most state-ofthe-art behavioural, pharmacological and clinical trial research in the USA.

In the UK, the terms "concordance" or "therapeutic alliance" have gained wide support because they suggest that "the work of the prescriber and patient in the consultation is a negotiation between equals and the aim is therefore a therapeutic alliance between them.
This alliance, may, in the end, include an agreement to differ. Its strength lies in a new assumption of respect for the patient's agenda and the creation of openness in the relationship, so that both doctor and patient together can proceed on the basis of reality and not of misunderstanding, distrust and concealment" [3].

Regardless of the terminology used, there has been increased recognition that effective interventions to promote appropriate use of prescribed medications in the management of chronic disease, must acknowledge and respect patient beliefs, abilities and therapeutic goals $[2,4,5]$.

\section{THERAPY ADHERENCE FOR ASTHMA AND COPD: SIMILARITIES AND DIFFERENCES}

Although standard treatment regimens for both asthma and chronic obstructive pulmonary disease (COPD) require patients to use several daily inhaled medications, delivered by either pressurised metered-dose inhalers (pMDIs), dry powder inhalers or nebulisers, COPD and its therapies differ markedly from asthma and its therapies in a number of ways. Asthma is an episodic, rarely life-threatening disease with effective controller and reliever therapies available that can generally allow patients to achieve total control of their disease. COPD, on the other hand, is a progressive, debilitating and often fatal disease with treatment options that can improve quality of life and reduce exacerbations, but cannot fully reverse or control disease symptoms. The nature of the disease, the treatment, and patient beliefs and expectations about therapy all combine to influence patient adherence to therapy [6].
CORRESPONDENCE

C.S. Rand

Johns Hopkins School of Medicine 5501 Hopkins Bayview Circle Baltimore MD 21224 USA Fax: 14105502612 E-mail: crand1@jhmi.edu 
As with other chronic treatment regimens, non-adherence with asthma and COPD therapy is widespread and, as such, is a significant risk factor for morbidity and mortality [7]. Conservative estimates indicate that almost half of the prescription medications dispensed each year for these conditions are not taken as prescribed. Non-adherence can take many forms: it can be a failure to collect the initial prescription (primary non-adherence), under-use of therapy (secondary non-adherence) or premature discontinuation of therapy. WATTS et al. [8] examined primary non-adherence in patients with asthma by matching prescriptions written to those collected over a 3-month period. The study included both new and repeat prescriptions for asthma medication. Of 359 documented prescriptions written, only 251 ( $\sim 70 \%)$ were collected. A similar study by KeLLOWAY et al. [9] found that the adherence rate for inhaled corticosteroids (ICS) among adult patients was $57 \%$ of prescribed. Since these adherence estimates are based on refill rates, they represent the maximum possible levels of adherence and do not provide any information on the day-to-day patterns of medication use in the home.

Even when patients collected prescriptions for medication, studies of secondary non-adherence (rates of medication use) suggest that long-term rates of adherence to preventive therapies (e.g. controller or preventer medications) among adult patients are low. Studies by SPECTOR et al. [10], MAWHINNEY and coworkers [11, 12], YEUNG et al. [13], RAND and coworkers [14-16] and others, which used electronic monitoring of pMDI dispensing, suggest that average adherence to asthma and COPD regimens is $<50 \%$ of prescribed, and may dip much lower [16]. Studies in both asthma and COPD also suggest that, while patients tend to under-use controller or maintenance therapies, symptom-relieving drugs such as bronchodilators are often overused [17, 18].

Only a limited number of studies have specifically examined patient adherence with COPD therapy. One of the earliest, a small study conducted by DOLCE et al. [19], examined selfreported adherence in 78 outpatients being treated at a medical centre in the south-eastern region of the USA. Patients reported that they were prescribed on average six medications, requiring different dosing regimens and modes of administration. Poor pMDI technique was common (31\%) and $>50 \%$ of patients reported regularly under-using prescribed medications. The study's authors did not find that prescription patterns or patient demographic variables were associated with adherence; however, patients did report that they were more likely to overuse rescue medications when they were experiencing respiratory distress.

While the DoLCE et al. [19] study described self-reported COPD adherence in a clinical setting, the Lung Health Study (LHS) [14] provided an opportunity to examine long-term, objectively measured adherence to inhaled COPD therapy (ipratropium bromide or placebo) in almost 4,000 participants in a clinical trial. The LHS was a double-blind, multicentre, randomised, controlled trial of smoking intervention and bronchodilator therapy as early interventions in COPD. Satisfactory or better adherence was reported by nearly $70 \%$ of participants at the 4 month follow-up visit, but declined to $\sim 60 \%$ over the next 18 months. Adherence classified by canister weight was satisfactory or better in $72 \%$ of participants who returned all canisters at 1 year, and in $70 \%$ of the participants who returned all canisters at the 2-year follow-up. Nevertheless, self-reporting confirmed by canister weight classified only $48 \%$ of participants at 1 year as showing satisfactory or better adherence. Multiple logistic regression analysis found that adherence was better in participants who were married, older, White and had more severe airway obstruction.

An ancillary adherence study within the LHS, which used electronic medication monitors, found that canister weight data significantly overestimated adherence: only $15 \%$ of the participants actually used the inhaler 2.5 or more times per day on average (the prescription was three uses per day). In addition, the study found that around $14 \%$ of participants appeared to be "dumping" medication prior to clinic visits (i.e. actuating their inhalers more than 100 times in a 3-h interval), in order to appear adherent. Analysis of electronic monitoring data collected over a period of 2 years from the LHS indicated that adherence to the prescribed medication regimen was at its best immediately following each clinic visit and gradually declined during the interval between visits. Moreover, the level of adherence after each visit was lower for each successive follow-up, going from a mean daily adherence of $1.6 \pm 0.85$ uses per day at 4 months to $1.16 \pm 0.95$ uses per day by 24 months. These trends could not be observed from either self-reporting or canister weights at follow-up visits [20].

Long-term patient adherence with ICS was also measured in the Detection, Intervention, and Monitoring Program for Asthma and COPD (DIMCA) study [21]. This was a prospective, randomised, placebo-controlled study of treatment with fluticasone propionate (via Flovent ${ }_{\circledR}$ Rotadisk ${ }_{\circledR}$; no longer in production from GlaxoSmithKline, North Carolina, NC, USA) in patients with asthma or early COPD. Forty-eight adults with early signs of COPD were enrolled in the trial. By taking measurements of medication use (i.e. counting the returned Flovent ${ }^{\circledR}$ Rotadisks $\left.₫\right)$, the mean overall adherence for these patients was found to be $72 \%$ (range, $7-102 \%$ ), and this level was maintained throughout the trial. This estimated adherence level is, however, likely to be a significant overestimatation of average patient adherence, as this method of measuring is vulnerable to dumping [15] and cannot be calculated for nonadherent patients who fail to return all their medication at clinic visits [14]. Neither perceived effectiveness nor sideeffects were related to adherence, although patient motivation (i.e. the willingness of patients to use the trial drug in daily practice) was found to be significantly related to adherence during the trial [21].

BLAIS et al. [22] examined trends in patient persistence with COPD treatments in a cohort of 3,768 physician-diagnosed, elderly Canadian COPD patients selected between 1990-1996. During this period, the proportion of patients who collected at least one prescription for ICS increased from $42.2 \%$ in 1990 to $53.1 \%$ in 1995 . Patients that were most likely to be started on ICS were those with more severe disease or those treated by a respirologist. However, the proportion of patients who persisted with ICS for $<1$ year increased from $47.6 \%$ in 1990 to $67.0 \%$ in 1995 . A similar cohort study performed in the USA in patients aged $\geqslant 65$ years with moderate or severe COPD, found that $\sim 60 \%$ were poorly adherent with ICS therapy [23]; notably, better adherence was associated with a $20 \%$ lower 
frequency of hospital visits in a year. A link between compliance and outcomes was also found in a study of 93 patients on home nebuliser therapy, in which 46 of 82 patients were found to be poorly compliant, with poor compliance being associated with impaired quality of life [24].

\section{INHALED THERAPY REGIMEN CHARACTERISTICS, PATIENT HEALTH BELIEFS AND ADHERENCE}

In general, research suggests that the lengthier and more complicated the treatment regimen, the greater the likelihood of non-adherence [1]. This observation has led to the expectation that simpler, once-daily therapies will inevitably lead to improved patient adherence. Retrospective studies based on review of pharmacy claims data do suggest some adherence advantage for once-daily therapies compared with therapies using twice-daily dosing [25]. However, while once-daily dosing may improve erratic non-adherence by simplifying daily regimens and decreasing the number of doses missed due to simple forgetfulness, this is unlikely to promote adherence in the rationally non-adherent patient (sometimes called deliberate or "intelligent" non-adherence) who is intentionally decreasing or discontinuing therapy because they believe that they no longer need to use it [26] or because they are concerned about side-effects [27].

Aside from adherence considerations, once-daily therapy appears to be preferred by most patients. VenABLEs et al. [28] examined patient preference in asthma therapy and found that $61 \%$ of patients expressed a preference for once-daily treatment, $12 \%$ preferred twice-daily treatment and $27 \%$ expressed no preference. While selecting therapies based on patient preference may not necessarily lead to improved adherence, it might reduce the burden of therapy and enhance a patient's quality of life.

Other characteristics of treatment regimens can also impair or enhance adherence. For example, adherence with inhaler therapies may be compromised by poor device technique (e.g. pMDI and peak flow monitoring) [29]. Actual or perceived side-effects or risks of treatment can also reduce adherence levels. Patients concerned by real or imagined risks of ICS may deliberately reduce dosing in an effort to decrease exposure [30]. The patient's understanding and beliefs about therapy can also influence adherence with treatment [6]. Asthma and COPD patients alike frequently misunderstand the purpose of prescribed therapy and confuse the side-effects of ICS with those of anabolic steroids [31]. The most frequent reason that patients cite for not using their therapy is a belief that they no longer need it or that it does not do any good [26]. Unwitting non-adherence, often due to the patient misunderstanding or forgetting the clinician's instructions, may occur even when physicians provide appropriate information and education during the consultation. Studies of how well patients retain health information suggest that immediately after an office visit, they recall $<50 \%$ of the information conveyed by the physician [32].

In addition to a general limitation to their ability to recall information, patients with lower health literacy (sometimes called "functional literacy") may inherently have more difficulty recalling and comprehending medical information. Such individuals may be at particular risk of non-adherence, caused by misunderstanding of the therapeutic regimen. A recent study of diabetic patients with poor health literacy showed that physicians very rarely checked patient recall of new concepts or explained them more clearly (fig. 1) [33].

\section{INTERVENTIONS AND EDUCATIONAL PROGRAMMES TO INCREASE PATIENT ADHERENCE IN COPD}

While many studies have examined strategies to improve adherence with therapy, few of these have focused on respiratory medications [34]. Self-management strategies for enhancing asthma medication adherence can include asthma education, self-monitoring (medication use and peak flow monitoring), inhaler technique, reinforcement, tailoring and cueing. Many of these interventions have been shown to work in studies of adults with asthma [34-36].

Studies of interventions to improve adherence and selfmanagement in COPD are very limited, however, and have yielded mixed findings to date [37-41]. One recent study by GALLEFOSS [37] reported promising results. This randomised controlled study evaluated the 12-month effectiveness of a selfmanagement education programme in patients with COPD. Sixty-two Norwegian outpatients with mild-to-moderate COPD were randomly assigned to either a 4-h group patient education session followed by up to two individual sessions, or a control group. Although no significant differences were observed between the groups with respect to ICS adherence at the 12-month follow-up, patients in the education group were dispensed less than half the amount of rescue medication given to the control group (fig. 2). In addition, patient education decreased the need for general practitioner (GP) visits during the 1-year follow-up by $85 \%$ (from 3.4 to 0.5 visits; $\mathrm{p}<0.001$ ), and a greater proportion of these patients became independent of their GP during the 12-month follow-up than in the control group ( $73 \%$ and $15 \%$, respectively). Patient education also improved satisfaction with the overall handling of their disease by their GP [37].

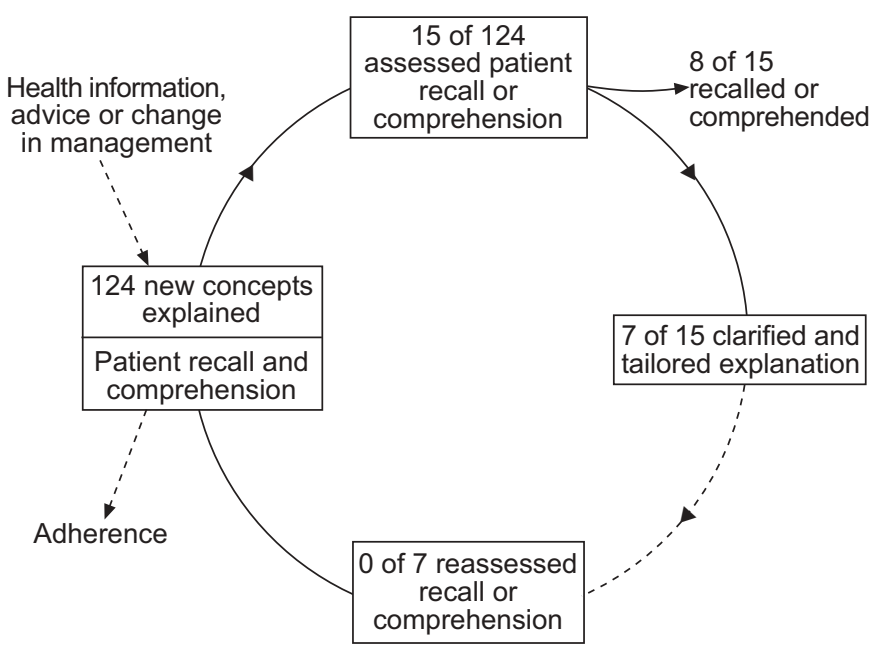

FIGURE 1. Failure to close the interactive loop in clinician-patient communication. Based on audio-taped consultations, the results reflect the extent to which 38 physicians assessed recall and comprehension of newly introduced disease management concepts among 74 diabetic patients with low health literacy. Reproduced from [33] with permission from the publisher. 


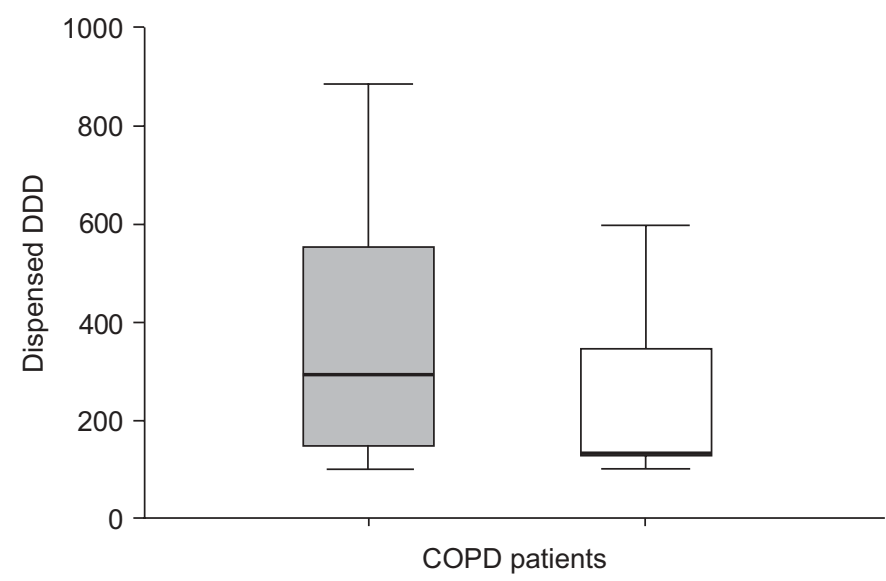

FIGURE 2. Quantity of short-acting $\beta_{2}$-agonists (number of defined daily dosages (DDD)) dispensed to patients over 12 months. $\square$ : patients who underwent a disease education programme; $\mathbf{~ : ~ c o n t r o l s ~ ( n o ~ p r o g r a m m e ) . ~ T h i c k ~ l i n e s ~ i n ~ b o x ~}$ plots represent the median. Upper whiskers show the 75th-90th percentile; lower whiskers show the 10th-25th percentile. $p=0.03$ with the Mann-Whitney U-test. $n=23$, control group; $n=24$, intervention group. Reproduced from [37] with permission from the publisher.

\section{CONCLUSION}

In contrast to asthma, the evidence base for adherence to therapy in chronic obstructive pulmonary disease patients is very thin. The limited data available suggest that, as in other chronic diseases, adherence is often poor, and this has a negative influence on outcomes. Poor adherence in chronic obstructive pulmonary disease patients seems to be influenced more by patient beliefs and coping behaviour than by demographical factors or disease severity. Attributes of the treatment regimen itself (e.g. dosing frequency and perceived side-effects) also influence adherence rates, and better education of patients is likely to help. However, more research is needed to determine which strategies will be most effective, and although the patient's preference for a specific type of inhaler might be expected to affect adherence, such a link has not yet been demonstrated.

\section{SUMMARY}

- Very few published studies focus on adherence to treatment regimens in chronic obstructive pulmonary disease, but evidence suggests adherence is poor.

- Patients' beliefs about their disease influence adherence rates.

- Healthcare professionals in primary or specialist care who are prescribing treatment should ask the patient about adherence as a vital part of the consultation.

\section{REFERENCES}

1 Sackett DL, Haynes RB. Compliance with therapeutic regimens. Baltimore, John Hopkins University Press, 1976.

2 Tilson HH. Adherence or compliance? Changes in terminology. Ann Pharmacother 2004; 38: 161-162.
3 From compliance to concordance: towards shared goals in medicine taking. A joint report by the Royal Pharmaceutical Society of Great Britain and Merck, Sharp, Dohme: The Society, 1997.

4 Bissell P, May CR, Noyce PR. From compliance to concordance: barriers to accomplishing a re-framed model of health care interactions. Soc Sci Med 2004; 58: 851-862.

5 Lask B. Compliance, adherence, concordance. $\mathrm{Br} J$ Psychiatry 1998; 173: 271-272.

6 Horne R, Weinman J. Patients' beliefs about prescribed medicines and their role in adherence to treatment in chronic physical illness. J Psychosom Res 1999; 47: 555-567.

7 Cochrane GM. Therapeutic compliance in asthma; its magnitude and implications. Eur Respir J 1992; 5: 122-124.

8 Watts RA, McLennan GBI, El-Saadi O. Do patients with asthma fill their prescriptions? A primary compliance study. Aust Fam Physician 1997; 26: 54-56.

9 Kelloway JS, Wyatt RA, Adlis SA. Comparison of patients' compliance with prescribed oral and inhaled asthma medications. Arch Intern Med 1994; 154: 1349-1352.

10 Spector SL, Kinsman R, Mawhinney H, et al. Compliance of patients with asthma with an experimental aerosolized medication: implications for controlled clinical trials. J Allergy Clin Immunol 1986; 77: 65-70.

11 Mawhinney H, Spector SL, Heitjan D, Kinsman RA, Dirks JF, Pines I. As-needed medication use in asthma usage patterns and patient characteristics. J Asthma 1993; 30: 61-71.

12 Mawhinney H, Spector SL, Kinsman RA, et al. Compliance in clinical trials of two nonbronchodilator, antiasthma medications. Ann Allergy 1991; 66: 294-299.

13 Yeung M, O'Connor SA, Parry DT, Cochrane GM. Compliance with prescribed drug therapy in asthma. Respir Med 1994; 88: 31-35.

14 Rand CS, Nides M, Cowles MK, Wise RA, Connett J. Longterm metered-dose inhaler adherence in a clinical trial. The Lung Health Study Research Group. Am J Respir Crit Care Med 1995; 152: 580-588.

15 Rand CS, Wise RA, Nides M, et al. Metered-dose inhaler adherence in a clinical trial. Am Rev Respir Dis 1992; 146: 1559-1564.

16 Rand CS, Wise RA. Adherence with asthma therapy in the management of asthma. In: Szefler SJ, Leung DYM, eds. Severe Asthma: Pathogenesis and Clinical Management. Lung Biology in Health and Disease. New York, Marcel Dekker, 1996; pp. 435-464.

17 Hand $\mathrm{CH}$, Bradley C. Health beliefs of adults with asthma: toward an understanding of the difference between symptomatic and preventive use of inhaler treatment. $J$ Asthma 1996; 33: 331-338.

18 Dekker FW, Dieleman FE, Kaptein AA, Mulder JD. Compliance with pulmonary medication in general practice. Eur Respir J 1993; 6: 886-890.

19 Dolce JJ, Crisp C, Manzella B, Richards JM, Hardin JM, Bailey WC. Medication adherence patterns in chronic obstructive pulmonary disease. Chest 1991; 99: 837-841.

20 Simmons MS, Nides MA, Rand CS, Wise RA, Tashkin DP. Trends in compliance with bronchodilator inhaler use between follow-up visits in a clinical trial. Chest 1996; 109: 963-968. 
21 van Grunsven PM, van Schayck CP, van Deuveren $M$, van Herwaarden CL, Akkermans RP, van Weel C. Compliance during long-term treatment with fluticasone propionate in subjects with early signs of asthma or chronic obstructive pulmonary disease (COPD): results of the Detection, Intervention, and Monitoring Program of COPD and Asthma (DIMCA) Study. J Asthma 2000; 37: 225-234.

22 Blais L, Bourbeau J, Sheehy O, LeLorier J. Inhaled corticosteroids in COPD: determinants of use and trends in patient persistence with treatment. Can Respir J 2004; 11: 27-32.

23 Balkrishnan R, Christensen DB. Inhaled corticosteroid use and associated outcomes in elderly patients with moderate to severe chronic pulmonary disease. Clin Ther 2000; 22: 452-469.

24 Corden ZM, Bosley CM, Rees PJ, Cochrane GM. Home nebulized therapy for patients with COPD: patient compliance with treatment and its relation to quality of life. Chest 1997; 112: 1278-1282.

25 Sherman J, Patel P, Hutson A, Chesrown S, Hendeles L. Adherence to oral montelukast and inhaled fluticasone in children with persistent asthma. Pharmacotherapy 2001; 21: 1464-1467.

26 Chambers CV, Markson L, Diamond JJ, Lasch L, Berger M. Health beliefs and compliance with inhaled corticosteroids by asthmatic patients in primary care practices. Respir Med 1999; 93: 88-94.

27 Boulet LP. Perception of the role and potential side effects of inhaled corticosteroids among asthmatic patients. Chest 1998; 113: 587-592.

28 Venables TL, Addlestone MB, Smithers AJ. A comparison of the efficacy and patient acceptability of once daily budesonide via Turbuhaler and twice daily fluticasone propionate via a disc-inhaler at an equal dose of $400 \mathrm{mcg}$ in adult asthmatics. Br J Clin Res 1996; 7: 15-32.

29 Shrestha M, Parupia H, Andrews B, et al. Metered-dose inhaler technique of patients in an urban ED: prevalence of incorrect technique and attempt at education. Am J Emerg Med 1996; 14: 380-384.

30 Apter AJ, Reisine ST, Affleck G, Barrows E, ZuWallack RL. Adherence with twice-daily dosing of inhaled steroids. Socioeconomic and health-belief differences. Am J Respir Crit Care Med 1998; 157: 1810-1817.
31 Boulet LP. Perception of the role and potential side effects of inhaled corticosteroids among asthmatic patients. Chest 1998; 113: 587-592.

32 Dimatteo MR. The Psychology of Health, Illness and Medical Care: An Individual Perspective. Pacific Grove, Brooks/Cole, 1991.

33 Schillinger D, Piette J, Grumbach $\mathrm{K}$, et al. Closing the loop: physician communication with diabetic patients who have low health literacy. Arch Intern Med 2003; 163: 83-90.

34 Onyirimba F, Apter A, Reisine S, et al. Direct clinician-topatient feedback discussion of inhaled steroid use: its effect on adherence. Ann Allergy Asthma Immunol 2003; 90: 411-415.

35 Bailey WC, Richards JM Jr, Brooks CM, Soong SJ, Windsor RA, Manzella BA. A randomized trial to improve self-management practices of adults with asthma. Arch Intern Med 1990; 150: 1664-1668.

36 Put C, van den BO, Lemaigre V, Demedts M, Verleden G. Evaluation of an individualised asthma programme directed at behavioural change. Eur Respir J 2003; 21: 109-115.

37 Gallefoss F. The effects of patient education in COPD in a 1-year follow-up randomised, controlled trial. Patient Educ Couns 2004; 52: 259-266.

38 Worth H, Dhein Y. Does patient education modify behaviour in the management of COPD? Patient Educ Couns 2004; 52: 267-270.

39 Hesselink AE, Penninx BW, van der Windt DA, et al. Effectiveness of an education programme by a general practice assistant for asthma and COPD patients: results from a randomised controlled trial. Patient Educ Couns 2004; 55: 121-128.

40 Monninkhof E, van der Valk $P$, van der Palen J, van Herwaarden C, Zielhuis G. Effects of a comprehensive self-management programme in patients with chronic obstructive pulmonary disease. Eur Respir J 2003; 22: 815-820.

41 Monninkhof E, van der Valk $P$, van der Palen J, van Herwaarden C, Partridge MR, Zielhuis G. Selfmanagement education for patients with chronic obstructive pulmonary disease: a systematic review. Thorax 2003; 58: 394-398. 